\title{
Experiences That Matter: Membership Involvement of Young Adult Members in Voluntary Sports Clubs in the Netherlands
}

\author{
Nanny Kuijsters-Timmers ${ }^{1,2, *}$, John Goedee ${ }^{2,3,4}$, Roger Th. Leenders ${ }^{3,4}$ \\ ${ }^{1}$ Department of Sports Marketing and Sports Communication (SPECO), Fontys University of Applied Sciences, Tilburg, the Netherlands \\ ${ }^{2}$ Tilburg School of Humanities and Digital, Tilburg University, Tilburg, the Netherlands \\ ${ }^{3}$ Tilburg School of Social and Behavioral Sciences, Tilburg University, Tilburg, the Netherlands \\ ${ }^{4}$ Jheronimus Academy of Data Science \& Tilburg School of Social and Behavioral Sciences, Tilburg University, 's-Hertogenbosch, the \\ Netherlands
}

\section{Email address:}

n.kuijsters@fontys.nl (N. Kuijsters-Timmers)

${ }^{*}$ Corresponding author

\section{To cite this article:}

Nanny Kuijsters-Timmers, John Goedee, Roger Th. Leenders. Experiences That Matter: Membership Involvement of Young Adult Members in Voluntary Sports Clubs in the Netherlands. Social Sciences. Vol. 10, No. 4, 2021, pp. 160-171. doi: 10.11648/j.ss.20211004.11

Received: May 28, 2021; Accepted: June 17, 2021; Published: July 6, 2021

\begin{abstract}
Many young people in the Netherlands participate in voluntary sports clubs (VSCs) but stop once they become adults. VSCs lack the ability to transition their youth members to adult members, which threatens the size of the clubs in terms of membership, the income, and the availability of volunteers. This research aims to identify experiences of young adult members that contribute to membership involvement (MI) and intentions to support the club and continue membership (membership commitment). A mixed-method approach consisting of a qualitative and a quantitative study was used. The results showed that young adult members elaborate on a wide range of experiences that predicts MI at four stages of membership. These experiences can be classified into the pleasure when participating in sports (enjoyment), the service and support within the club (care), and the social connectedness among the members (closeness). Moreover, the results revealed that MI performs as a mediator for membership commitment. The conclusion indicates that experiences of young adult members are integrated system, one cannot do without the other. This integrative system of experiences determines membership involvement in all stages of membership, from less than one year to long-term memberships. For clubs it is important to address these experiences because MI is important for the development of membership commitment - loyal and supportive young adult members.
\end{abstract}

Keywords: Organized Sports, Involvement Theory, Young Adults Membership

\section{Introduction}

About $70 \%$ of children and teenagers in the Netherlands participate in sports through membership of voluntary sports clubs (VSCs). Once they are young adults (18 - 29 years old), this drops to $30 \%$ [42]. Compared with other age groups, this is the largest declination of memberships of a VSC including student sports clubs [42]. International studies also show diminished memberships of VSCs among young adults [10, $12,34,40]$. Outflow of young adult members is one of the main causes of decreasing membership that the clubs are facing [10, 30, 41]. This decreasing membership has negative consequences for the clubs' organizational effectiveness, such as a lower inflow of membership fees and fewer volunteers to perform tasks $[54,55,58]$.

In order to mitigate this trend of outflow of young adult members, it is important to understand which experiences within this age group are essential for their membership involvement (MI), and the positive orientation to their sports club during membership [20,28,], which is the aim of this research. Experiences while participating in sports, afterwards at the clubhouse also called the 'third half', or during other activities related to the sports could be important 
indicators of MI of young adults members [18, 34, 51]. However, little research has tapped into the membership involvement of young adult members and how this can be developed over time. Insights into MI and the underlying experiences can enhance understandings of young adults' motives to continue as a member and support the club (membership commitment). For the governance of VSCs, these insights can be useful, because the members are not only consumers, but also producers of the sports service [16, 2014 , p. 133 S]. Moreover, understanding MI could be helpful in deepening the knowledge of the specific nature of the positive orientation of members to their member organizations. As previous research on member retention and volunteers suggest, involvement could be a central factor, but it is not yet clarified which experiences are relevant in the case of young adults [48, 56, 58]. Therefore, MI of young adults, its predictors and outcomes have been explored, based on the experiences in the VSCs. In a mixed method design, the following research questions were addressed: (1) what are the experiences of young adult members in VSCs that underlie membership involvement in order to identify beliefs; (2) to what extent are these beliefs related to young adults' membership involvement and commitment to voluntary sports clubs?

\subsection{Experiences of Members That Contribute to Membership Involvement}

Participation in sport through membership of a voluntary sports club is regarded as a healthy and enjoyable pastime $[17,52,60]$. For a long time, it has been the only way to participate in sport in Western Europe. Changing patterns of leisure activities, have yielded alternatives to VSCs, such as fitness centers, or non-organized sports. The need for individual choices can be seen as one of the rationales for changes in leisure activities, and this need is certainly felt by young adults [19, 23, 56]. In tourism and leisure, the consumer experience has increased in value compared to the product or service itself $[26,33]$. It is unclarified whether this shifted the balance from 'service delivery' to 'offering experiences' is of importance within the voluntary sports clubs. Previous research into involvement in the context of VSCs mainly focuses on people's motives and attitudes to participate in a sport [5, 24, 38, 49]. Members can construct experiences while participating in sports but also outside the training sessions and matches [1, 20, 62]. This may imply that the relationship of members with their VSCs not only refer to the sport itself but also to other aspects. Therefore, MI should include also non-sport-related experiences within VSCs. In order to explore non-sport-related experiences of young adult members, our research to membership involvement focused on all experiences during membership.

The objective of this research is to identify experiences that contribute to MI, which refers to the positive orientation of members to their club [20]. Involvement can be defined as the willingness to engage in activities that support the organization's objectives $[20,27]$, or the enthusiasm, affection, and dedication to an organization [28]. Because this orientation is built on experiences, membership involvement may be envisioned as a kind of 'reward' that occurs when members like what they experience in their VSCs $[6,37]$. The concept 'experience' is complex and refers to observations and perceptions that provoke individual responses on cognitive, affective, social, and psychological levels [23, 26, 62]. Functional service elements along with emotional and affective connections play a role in building up members' experiences within VSCs, such as environmental settings, the context, social actors, and social interactions with other members [23, 47]. In his work, Weick $[62,63]$ captures experiences as drivers to beliefs, which he explains as a kind of 'default state': 'to see and hear something, is to believe it immediately' [63, p. S12]. Beliefs can be resources for the sensemaking of members regarding their organization $[61,62]$. This concept of sensemaking, or given a meaning, can be linked to the concept membership involvement because both concepts express the positive orientation of members to their organizations to members based on experiences [20,62]. For members, it is difficult to objectively report experiences because observations cannot be separated from individual expectations, which function as filters that interpret observed actions and situations [61, 62].

Exploring the beliefs of young adult members, based on experiences and expectations, can advance the understanding of MI. Because members are both producers and consumers of the sports service, the membership in a sports club implies investment of time (e.g., participating in sports, doing voluntary tasks) and money (e.g., membership fees). In return, the experiences in their club (e.g., consumption of sports and social services, social contacts, appreciation by other people etc.) has to satisfy the member's interests [51]. Experiences within VSCs refer to 'skill-development' [22], 'enjoyment and pleasure' [2, 50], 'influence or need fulfilment' [40], doing voluntary tasks within the sports club $[18,48]$ or 'having social contacts' and 'meeting friends' [39, 51]. Especially to young adults dropouts from organized sport, the lack of positive experiences as a member was found to be an important indicator for leaving the club [12]. Our research aims to give insights into young adult members' experiences in order to depict the beliefs regarding membership involvement.

One can argue that relatively new members' observations and perceptions are distinct from those with long-term memberships $[34,50]$. Therefore, this study also includes the impact of the length of young adults' membership on MI. Research in commercial contexts shows that the attachment with a brand or product is the result of long-term positive experiences of consumers [26, 59]. Although the duration of the membership appeared to be important in relation to volunteering and staying as a member in general $[11,51]$, there is a lack of insight into the relationship between duration and membership involvement as the positive orientation of young adult members with their VSCs.

\subsection{Support and Loyalty}

Understanding the MI can be helpful in reversing the 
declining trend in membership, especially among young adults, and the reduced support of members as volunteers that the clubs face in most European countries as a consequence $[10,30]$. In the field of organized sports, members' support and loyalty are described as membership commitment [51, 58]. In general, commitment is conceptualized in a proliferation of terms that refer to the bonding of members to the club [14, 18] and the intensity of the bond, which depends on the degree to which one's intentions to behave are consistent with the VSCs' behavioral demands [44]. Commitment can arise as a result of members' positive orientation to the organization- that we define as membership involvement - which fosters members' contributions to the VSCs' objectives $[48,52,58]$. This loyalty and supportive behavior is increasingly linked to the experiences of the members, especially in the case of young adults [23, 34, 40, 51]. Since it is assumed that MI of members arises from members' experiences and that members' experiences and MI of members contribute to membership commitment, it is to be expected that MI of members serves as a mediator in the development of membership commitment. From these rationales, the objective in this study is to explore MI among young adult members, based on experiences and functioning as a mediator to membership commitment in the four stages of membership.

\section{Method}

To answer the research questions an exploratory sequential mixed method research has been employed [13, 21]. In this type of design, the findings from the first study with a qualitative approach are used to feed the subsequent quantitative study. [21]. This design allows to first elicit experiences to identify beliefs related to involvement (study 1) followed a by the measuring of relationships between beliefs (study 2). In developing a reliable measuring instrument, the eight steps for scale development of DeVellis [15] were followed: (1) determining clearly what it is you want to measure, (2) generating an item pool, (3) determining the format for measurement, (4) having the initial item pool reviewed by experts, (5) considering inclusion of validation items, (6) administering items to a development sample, (7) evaluating the items and (8) optimizing scale length. Criterion sampling was used for the participants of this study to be selected, because previous research revealed that young adults, in particular, form a risk group regarding the continuation of membership [10, 12, 34].

\subsection{Study 1: Identifying Experiences Related to Membership Involvement}

\subsubsection{Participants and Procedure}

In order to identify the experiences regarding membership involvement of young adults (RQ1), 28 members (11 males, 17 females) of VSCs in the southern part of the Netherlands participated, ranged in the age between 15 and 26 years $(M=$ 21,04, $S D=3,16)$. Participants were all members of one or more VSC (football, tennis, field hockey, ice hockey, korfball, rowing, and cycling). Open-ended questions aimed to elicit observations and individual perceptions (see Appendix A for the questionnaire). After completion, the answers were discussed with the participant to ensure that the answers would be correctly interpreted by the researchers. Next, an inductive data analysis was performed using the thematic method according to Braun \& Clarke [9]. After familiarization with the data, phrases were labelled that referred to experiences related to MI in several coding rounds. Overarching themes were assigned to coherent groups of labelled phrases. To improve the credibility of this data reduction, a second assessor independently coded the answers of three of the participants, which resulted in minor changes to the original coding scheme [43]. As a result of this data reduction process, the themes were considered as sensitizing concepts of MI. As opposed to definite concepts that offer clear definitions, sensitizing concepts allow for a general sense of reference and guidance in approaching empirical instances and, thus, merely 'suggest directions along which to look' [7, p. 7, 8]. Therefore, sensitizing concepts offer ways of seeing, organizing, and understanding the collected experiences of the participants.

\subsubsection{Findings}

Seven distinct types of sensitizing concepts of membership involvement of young adults emerged, based on the interpretation of the participants' experiences: (1) participation, (2) service, (3) dedication, (4) enjoyment, (5) togetherness, (6) acknowledgement, and (7) identification. The sensitizing concepts referred to observations and interpretations of situations and were characterized by positive experiences mentioned by the participants. Additionally, participants described some negative experiences or situations, which ensures a balanced depiction.

The sensitizing concept participation refers to the attendance of members in sports and other club activities, watching matches, or partaking in voluntary tasks and decision making as members of boards or committees. 'You can often find them at the club ( $\left.\mathrm{p}^{1} .8\right)$ and 'they are active in volunteering alongside their own sports activities' (p. 19). Additionally, duration of the membership and the intensity of membership were frequently mentioned, sometimes expressed in knowing how things work at the club. As a participant (p. 14) said: 'people who generally have been with the club for a long time and grasp how things work within the club'. Participants also mentioned reasons for not actively participating within the club, such as 'because the team is less enjoyable' (p. 7), 'too little influence (p. 22, p. 28 ) or too little time to spend at the club (8 participants).

Participants experience good service when a club is well organized and coordinated. Participants frequently relate this experiential dimension to proper organization and efficient

\footnotetext{
1 'p' stands for participant
} 
internal communication: 'clear volunteer tasks for a fee' ( $\mathrm{p} 4$, p. 16 , p. 20 , p. 21$)$; 'the activities, the educational programs, and the internships for volunteers that the club offers' (p. 12). Lack of service was related to no fee for voluntary tasks, bad governance of the club, poor internal communication but also 'feeling pressed to volunteer' (p. 2, p. 21)

The sensitizing concept dedication refers to a sense of loyalty and support. Participants mentioned the willingness to put time and effort in the club, doing tasks on a voluntary basis, knowing what is going on in the club and feeling responsible. As a participant stated: 'At times when the club is less successful, they are the first to come up with a solution or help' (p. 14) and 'Doing something for someone else is what drives them, by offering youth members the same things they enjoyed when they were young themselves' ( $p$. 23). Participants also mentioned that this support and loyalty takes time and costs money and it 'feels as an obligation to do voluntary tasks when you do not have a nice time' (p. 7).

Enjoyment refers to the cozy and pleasant atmosphere of a voluntary sports club and the attitude members adopt as a result, such as 'the club is not only as a place where you can play sports, but also a place where you stay with friends' (p. 14). Important to participants is the positive ambiance, feeling welcome, the pleasure of playing sports at the club and networking at the same time 'having fun while meeting people' (p. 8, p. 26). Negative experiences characterized the opposite of this sensitizing concept, such as bad ambiance, or not playing in a team with a pretty atmosphere and the perception of a negative ambiance.

Togetherness refers to the sensitizing concept that tells us about the unity and solidarity among members. Participants described being socially connected and feeling included. This is frequently illustrated by experiences as being and playing together, sharing the same objectives and responsibility towards the club, which jointly create a sense of social cohesion. Participants mentioned, for example, 'members have more or less the same ideas about the club' (p. 9) and 'that creates a sense of solidarity' (p. 19). Participants stated that the opposite of togetherness occurs when members experience exclusion ('not being part of social circles', p. 8) or when the focus is on the top teams.

The sensitizing concept acknowledgement is about receiving appreciation, being taken seriously, gaining trust, belonging, and experiencing friendship, but also about 'open-minded meetings that show that everyone's opinion counts' (p. 7). Ultimately, this can result in bonding between the members and in the emergence of social networks within the sports club. As participants reported: 'the social aspects that play a role within a club, creating unity and a bond within the club' (p. 17, p. 21). The negative dimension of acknowledgement reflects the sense of being disrespected.

Identification is the sensitizing concept that indicates even more strongly the perceived position of a member in relation to the sports club than the sensitizing concept of acknowledgement does. Examples are the feelings of 'being at home' (p. 13), belonging to the club (p. 20), and 'you literally feel part of the club' (p. 14). Furthermore, a participant mentioned 'the one's identification with the external image of the club' (p. 19) Participants stated experiences that result in 'feeling safe and secure' (p. 26, p. 29) but also 'the commitment you feel because you belong to the club' (p. 16).

\subsubsection{Conclusions}

The objective of the first study is to understand the members' beliefs regarding MI. The seven sensitizing concepts reflect these beliefs, based on experiences of the members. Together, these beliefs define the aspects of membership involvement and yield more elaborated insights. First, MI is associated with participation in sport or non-sport related activities. The duration of membership seems to play a role, which is in line with research on volunteering within VSCs [11, 51]. Additionally, MI refers to experiencing that the club is a well-managed organization (service) and to a willingness of members to support the club by doing tasks (dedication). These aspects, referring to the care of members within a club, give a more profound understanding of the roles of members as producers and consumers in VSCs than we found in the literature regarding, for example, volunteer engagement (cf 18, 58]. Finally, as more affectional aspects, participants described experiences of pleasure and a pleasant atmosphere (enjoyment), unity and solidarity (togetherness), with appreciation and trust (acknowledgement) and identifying with the club and its members (identification). These sensitizing concepts together indicate that participating in sports in a friendly atmosphere with positive social contacts is important. These aspects of closeness are also known from literature on social cohesion and a sense of community in sports [cf 35,60$]$.

\subsection{Study 2: Examining MI}

Next step is to determine to what extent the beliefs (sensitizing concepts in study 1) are related to membership involvement and commitment to VSCs in four stages of membership (RQ2). Study 2 aims to fill this gap by (1) comparing the relationships of membership involvement with the underlying predictors and the outcome 'membership commitment' (supportive and loyal membership), (2) determining whether MI can function as a mediating factor for membership commitment, and (3) investigating the influence of duration of membership by measuring in four stages of membership ( $<1$ year, 1-5 years, $6-10$ years and $>10$ years membership).

\subsubsection{Questionnaire and Content Validity}

Following the steps of scale development of DeVellis [15], the sensitizing concepts were used to feed the item pool to be generated (step 2 and 3). Each sensitizing concept was interpreted and transferred into a few items (e.g., dedication: 'I'm interested in what goes on in our club', 'I am quite willing to do volunteer work for the club', etc.). Moreover, several control items were added, such as 'I don't like obligatory tasks' (see Table 1). Since in exploratory sequential methods for each study the data is derived from 
different samples and the richness of qualitative data from study 1 is used for data to be quantitatively assessed in study 2 , the validity of the content is assumed $[13,21]$. To ensure the validity, step 4, two content validity tests were employed based on expert judging [15]. With three experts in the field of sports and cognitive sciences, we discussed our notes collected in study 1 and the sensitizing concepts [53]. Second, the experts checked and discussed our questionnaire [29].

Table 1. Overview of the items of study 2, which were feed by the sensitizing concepts of study 1 .

\begin{tabular}{|c|c|}
\hline Sensitizing concepts of study 1 & Items in study 2 \\
\hline Acknowledgement & $\begin{array}{l}\text { In my experience here, every individual count } \\
\text { There is a lot of appreciation for what I do for the club } \\
\text { I don't have a say, board decides everything }\end{array}$ \\
\hline Dedication & $\begin{array}{l}\text { I'm going to put more posts up on the social media of my club } \\
\text { I don't like obligatory tasks } \\
\text { I am quite willing to do volunteer work for the club } \\
\text { I intend to become active for our club as a volunteer } \\
\text { I'm interested in what goes on in our club } \\
\text { Involvement is unnecessary }\end{array}$ \\
\hline Enjoyment & $\begin{array}{l}\text { I have a lot of fun at our club } \\
\text { Involvement in the club is nice } \\
\text { Involvement in the club is fun } \\
\text { Involvement is hard } \\
\text { I think there is a friendly atmosphere within our club }\end{array}$ \\
\hline Identification & $\begin{array}{l}\text { Ours is a pleasant club } \\
\text { Involvement in the club is pleasant } \\
\text { I'll still be a member of our club next year } \\
\text { Regardless of whether things at the club are going well }\end{array}$ \\
\hline Participation & $\begin{array}{l}\text { I'm taking part in training sessions and competitions } \\
\text { I read posts of our club on social media } \\
\text { Involvement is time-consuming } \\
\text { I'll get to know people in our club }\end{array}$ \\
\hline Service & $\begin{array}{l}\text { Membership of the club involves many unpleasant tasks } \\
\text { The club organizes a lot of fun activities } \\
\text { Club makes it possible to engage in enjoyable activities }\end{array}$ \\
\hline Togetherness & $\begin{array}{l}\text { There's a great deal of community spirit in our club } \\
\text { The atmosphere at the club is always pleasant } \\
\text { I feel free to state my opinions } \\
\text { I learn a lot from other members in our club } \\
\text { I met a lot of interesting people through the club } \\
\text { There's a great deal of community spirit in our club } \\
\text { The atmosphere at the club is always pleasant }\end{array}$ \\
\hline
\end{tabular}

\subsubsection{Procedure and Participants}

The questionnaire was completed by 1,009 participants (537: female; 472: male), aged 18 to 24 years $(78.3 \%)$, younger than 18 years $(3.7 \%)$, or older than 24 years $(18.0 \%)$. Participants were members of a voluntary sports club for less than 1 year $(8.5 \%), 1-5$ years $(22.5 \%), 6-10$ years $(20.2 \%)$ or more than 10 years $(48.8 \%)$. The practiced sports were football (43.4\%), field hockey (16.6\%), volleyball $(9.3 \%)$, tennis $(6.6 \%)$, korfball $(5.0 \%)$, handball
(4.6\%) and other sports $(0.5 \%$ to $3 \%)$.

Data reduction was performed through an exploratory factor analysis (principal component analysis with promax rotation, see Table 2), and based on these components were constructed. Cronbach's alphas of the aggregated variables in each component were deemed acceptable (ranging from 0.63 to 0.84 ) and the scores of the One Sample $t$-Test confirm that the components can be used for further testing, except the component 'constraints' (- 60.43).

Table 2. Factor analyses, reliability analyses, $t$-tests of the components.

\begin{tabular}{|c|c|c|c|c|c|c|}
\hline Components & Items & Factor loading & Reliability (CA) & t-test* & df & $\mathbf{p}$ \\
\hline Membership & & & .76 & 92,4 & 1008 & .000 \\
\hline \multirow[t]{3}{*}{ Involvement } & I have a lot of fun at our club & .719 & & & & \\
\hline & I am taking part in training sessions and competitions & .672 & & & & \\
\hline & The atmosphere at the club is always pleasant & .603 & & & & \\
\hline \multirow[t]{4}{*}{ Closeness } & & & .84 & 41.50 & 1008 & .000 \\
\hline & In my experience here, every individual count & .820 & & & & \\
\hline & There's a great deal of community spirit in our club & .595 & & & & \\
\hline & I think there is a friendly atmosphere within our club & .552 & & & & \\
\hline
\end{tabular}




\begin{tabular}{|c|c|c|c|c|c|c|}
\hline Components & Items & Factor loading & Reliability (CA) & t-test* & df & $\mathbf{p}$ \\
\hline \multirow[t]{4}{*}{ Membership } & & & .76 & $92, .4$ & 1008 & .000 \\
\hline & Ours is a pleasant club & .480 & & & & \\
\hline & There is a lot of appreciation for what I do for the club & .479 & & & & \\
\hline & I learn a lot from other members in our club & .323 & & & & \\
\hline \multirow[t]{4}{*}{ Enjoyment } & & & .63 & 77.63 & 1008 & .000 \\
\hline & Involvement in the club is nice & .793 & & & & \\
\hline & Involvement in the club is fun & .782 & & & & \\
\hline & Involvement in the club is pleasant & .709 & & & & \\
\hline \multirow[t]{7}{*}{ Care } & & & .82 & 22.11 & 1008 & .000 \\
\hline & I'm going to put more posts up on the social media of my club & .759 & & & & \\
\hline & I met a lot of interesting people through the club & .711 & & & & \\
\hline & I read posts of our club on social media & .651 & & & & \\
\hline & I'll get to know people in our club & .530 & & & & \\
\hline & The club organizes a lot of fun activities & .464 & & & & \\
\hline & Club makes it possible to engage in enjoyable activities & .401 & & & & \\
\hline \multirow[t]{8}{*}{ Constraints } & & & .69 & -60.43 & 1008 & .000 \\
\hline & I don’t like obligatory tasks & .810 & & & & \\
\hline & Membership of the club involves many unpleasant tasks & .789 & & & & \\
\hline & Involvement is hard & .249 & & & & \\
\hline & Involvement is unnecessary & .248 & & & & \\
\hline & Regardless of whether things at the club are going well & .242 & & & & \\
\hline & Involvement is time-consuming & .237 & & & & \\
\hline & I don't have a say, board decides everything & .235 & & & & \\
\hline \multirow{5}{*}{$\begin{array}{l}\text { Membership } \\
\text { commitment }\end{array}$} & & & .80 & 27.21 & 1000 & .000 \\
\hline & I am quite willing to do volunteer work for the club & .688 & & & & \\
\hline & I intend to become active for our club as a volunteer & .524 & & & & \\
\hline & I'm interested in what goes on in our club & .520 & & & & \\
\hline & I'll still be a member of our club next year & .459 & & & & \\
\hline
\end{tabular}

Table 3 presents descriptive statistics and Pearson correlations. It is noticeable that both membership involvement and membership commitment significantly correlate with the components 'enjoyment', 'closeness', 'care' and the control component 'constraints', although the latter showed negative correlations that indicates an inverse relationship. This can be interpreted as when the influence of the component 'constraints' increase, the other components will decrease and vice versa (see Table 3).

The One Sample $t$-Test and the descriptive statistics from the Pearson correlations give grounds not to include the component 'constraints' in the further analyses.

Table 3. Descriptive statistics and Pearson correlations.

\begin{tabular}{|c|c|c|c|c|c|c|c|}
\hline & $\mathbf{M}$ & SD & (MI) & (MC) & $(\mathbf{C L})$ & $(\mathbf{E N})$ & (CA) \\
\hline Membership Involvement (MI) & 3.72 & .418 & & & & & \\
\hline Membership Commitment (MC) & 3.06 & .658 & $.455^{* *}$ & & & & \\
\hline Closeness (CL) & 3.28 & .597 & $.566^{* *}$ & $.584 * *$ & & & \\
\hline Enjoyment (EN) & 3.67 & .480 & $.385 * *$ & $.402 * *$ & $.390 * *$ & & \\
\hline Care (CA) & 2.89 & .569 & $.493 * *$ & $.575 * *$ & $.635 * *$ & $.373 * *$ & \\
\hline Constraints $(\mathrm{CO})$ & 1.61 & .469 & $-.367 * *$ & $-.528 * *$ & $-.562 * *$ & $-.530 * *$ & $-.464 * *$ \\
\hline
\end{tabular}

** $p=0.01$.

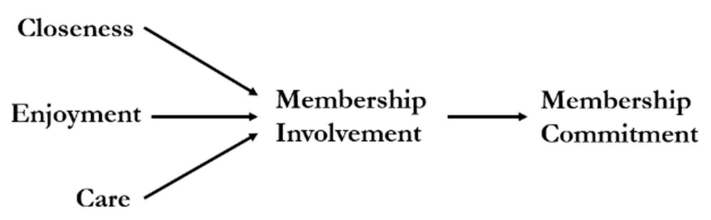

Figure 1. Conceptual model membership involvement of members in voluntary sports clubs (MI).

\subsubsection{Conceptual Model}

To determine the relationships of the components and the mediating factor of membership involvement a conceptual model was constructed (see Figure 1) that is grounded in the sensitizing concepts of study 1 and the results the data reduction (see Table 2). In this model, we propose the mediator component 'membership involvement', the outcome component 'membership commitment' and the predictor components 'closeness', 'enjoyment' and 'care'.

\section{Results}

Examining the relationships of membership involvement. To understand the relationships between membership involvement and both the predictive components and membership commitment, we conducted two regression analyses. In the 
case of membership involvement, we found high and significant regressions with significant unstandardized Beta coefficients $\left(\mathrm{R}^{2}=.373, \mathrm{p}<.001\right.$; closeness $\mathrm{B}=.39, \mathrm{p}<.001$; enjoyment $\mathrm{B}=.18, \mathrm{p}<.001$ and care $\mathrm{B}=.19, \mathrm{p}<, 001$. In the case of membership commitment, we found high and significant regressions with significant unstandardized Beta coefficients $\left(\mathrm{R}^{2}=.461, \mathrm{p}<.001\right.$; membership involvement $\mathrm{B}$ $=.15, \mathrm{p}<.01$; closeness $\mathrm{B}=.32, \mathrm{p}<.001$; enjoyment $\mathrm{B}=.20$, $\mathrm{p}<.01$ and care $\mathrm{B}=.33, \mathrm{p}<.001$. Membership involvement can thus be predicted by a combination of the components closeness, enjoyment, and care although limited by constraints. The combination of membership involvement and the components predict membership commitment.

Membership involvement as a mediating factor. To examine the mediating effect of membership involvement on membership commitment, the Process macro [46] was used (see Table 4). Closeness, enjoyment, and care predicted membership commitment, partially mediated by membership involvement. The mediation analysis shows that, in all cases, membership involvement partially explains membership commitment, thus, membership involvement is an important but not the only factor for developing membership commitment.

Table 4. Total, direct and indirect effects on membership commitment, mediated by membership involvement.

\begin{tabular}{|c|c|c|c|c|c|c|c|}
\hline & & $R^{2}$ & $B$ & $p$ & Boot LLCI & Boot ULCI & Interpretation \\
\hline \multirow[t]{4}{*}{ Closeness } & & .342 & & .000 & & & \\
\hline & Total effect & & .65 & .000 & & & \\
\hline & Direct effect & & .53 & .000 & & & \\
\hline & Indirect effect & & .12 & & .0670 & . 1690 & Partial mediation* \\
\hline \multirow[t]{4}{*}{ Enjoyment } & & .161 & & .000 & & & \\
\hline & Total effect & & .56 & .000 & & & \\
\hline & Direct effect & & .37 & .000 & & & \\
\hline & Indirect effect & & .18 & & 1317 & 2416 & Partial mediation* \\
\hline \multirow[t]{4}{*}{ Care } & & .330 & & .000 & & & \\
\hline & Total effect & & .66 & .000 & & & \\
\hline & Direct effect & & .53 & .000 & & & \\
\hline & Indirect effect & & .13 & & 0867 & .1746 & Partial mediation* \\
\hline
\end{tabular}

*partial mediation: a direct as well as an indirect effect on membership commitment.

Influence of duration of membership. Results are reported for the total sample without the factor 'duration of membership'. Since this emerged as an important factor for membership involvement in our study 1, we wanted to determine the impact of the duration of membership.
Therefore, the components for the four membership groups ( $<1$ year, 1-5 years, 6-10 years and $>10$ years) were explored by means of regression analyses. The means of all stages of membership, confirmed that duration of membership plays a role (see Table 5).

Table 5. Means (Standard deviations) of the components.

\begin{tabular}{|c|c|c|c|c|}
\hline & $<1$ year & 1-5 years & 6-10 years & $>10$ years \\
\hline Membership Involvement & $3.62(.541)$ & $4.67(.443)$ & $3.73(.416)$ & $3.75(.378)$ \\
\hline Closeness & $3.33(.621)$ & $3.29(.608)$ & $3.25(.604)$ & $3.28(.586)$ \\
\hline Enjoyment & $3.56(.599)$ & $3.62(.575)$ & $3.69(.345)$ & $3.71(.416)$ \\
\hline Care & $2.92(.628)$ & $2.92(.628)$ & $2.86(.547)$ & $3.89(.537)$ \\
\hline Membership Commitment & $2.85(.668)$ & $3.00(.646)$ & $2.94(.701)$ & $3.19(.620)$ \\
\hline
\end{tabular}

With regression analyses, we examined the prediction of membership involvement and membership commitment in each stage of membership. In each stage of the membership, we captured high and significant results for MI $\left(R^{2}: .593\right.$ in $<1$ year; .464 in $1-5$ years; .267 in $6-10$ years and .353 in $>10$ years, all $p<.001)$. Moreover, high, and significant results were found for membership commitment $\left(R^{2}: .403\right.$ in $<1$ year; .547 in $1-5$ years; .486 in $6-10$ years and .470 in $>10$ years, all $p<.001)$. In every stage, MI and membership commitment is predicted by a combination of the components.

To determine whether membership commitment can be developed under influence of membership involvement in each stage, mediation analyses were conducted using Baron \& Kenny's [3] 'causal steps method' for mediation in three stages (see Table 6). First, satisfying the first condition of mediation, closeness, enjoyment, and care, predicted membership commitment in each of the four stages (directs effects in step one, Table 5). Subsequently, the direct link between the hypothesized mediating factor (membership involvement) and membership commitment showed positive results on membership commitment in the four stages of membership (step one in Table 6), which satisfied the second condition. Second, the results indicated that the predictors (closeness, enjoyment, and care) of direct membership involvement, which satisfied the third condition of mediation (step two, Table 6). Third, each predictor was regressed on membership commitment with the mediator (membership involvement) included in the model. As shown in Table 5, all the components (closeness, enjoyment, and care) demonstrated a positive and significant influence on membership commitment (step three, Table 6).

According to Baron and Kenny [3] at least partial 
mediation is present if the first three conditions hold, which they did. After entering the mediating factor (membership involvement), the components remained as significant predictors of membership commitment, except the component enjoyment in stage $<1$ year. Following Baron and Kenny [3], this suggests the existence of partial mediation for all the predictors, with the exception of enjoyment in stage $<1$ year, which was completely mediated by membership involvement.

Table 6. Effect of each component (standardized Beta coefficients) on Membership commitment (MC) with membership involvement (MI) as a mediator in in the four stages of membership.

\begin{tabular}{|c|c|c|c|c|c|}
\hline & \multicolumn{2}{|l|}{ Step 1} & \multirow{2}{*}{$\begin{array}{l}\text { Step } 2 \\
\text { MI }\end{array}$} & \multirow{2}{*}{$\begin{array}{l}\text { Step } 3 \\
\text { MC }\end{array}$} & \multirow[t]{2}{*}{ interpretation } \\
\hline & MC & MC & & & \\
\hline \multicolumn{6}{|l|}{ Membership stage $<1$ year } \\
\hline Membership Involvement (MI) & & $.51 * * *$ & & & \\
\hline Closeness & $.57 * * *$ & & $.68 * * *$ & $.41 * *$ & Partial mediation \\
\hline Enjoyment & $.43 * * *$ & & $.60 * * *$ & .20 & Complete mediation \\
\hline Care & $.57 * * *$ & & $.63 * * *$ & $.41 * *$ & Partial mediation \\
\hline \multicolumn{6}{|l|}{ Membership stage $1-5$ years } \\
\hline Closeness & $.68 * * *$ & & $.65 * * *$ & $.58 * * *$ & Partial mediation \\
\hline Enjoyment & $.40 * * *$ & & $.35 * * *$ & $.25 * * *$ & Partial mediation \\
\hline Care & $.64 * * *$ & & $.58 * * *$ & $.50 * * *$ & Partial mediation \\
\hline \multicolumn{6}{|l|}{ Membership stage $6-10$ years } \\
\hline Membership Involvement (MI) & & $.47 * * *$ & & & \\
\hline Closeness & $.54 * * *$ & & $.46 * * *$ & $.41 * * *$ & Partial mediation \\
\hline Enjoyment & $.33 * * *$ & & $.32 * *$ & $.20 * *$ & Partial mediation \\
\hline Membership Involvement (MI) & & $.39 * * *$ & & & \\
\hline Closeness & $.60 * * *$ & & $.56 * * *$ & $.54 * * *$ & Partial mediation \\
\hline Enjoyment & $.43 * *$ & & $.36 * * *$ & $.34 * *$ & Partial mediation \\
\hline Care & $.57 * * *$ & & $.46 * * *$ & $.50 * * *$ & Partial mediation \\
\hline
\end{tabular}

Note $1: \mathrm{NS} ; * p<.05 ; * * p<.01 ; * * * p<.001$.

Note 2: Step 1 = without MI in the model (total effect); step $3=$ with MI in the model (indirect effect).

The analyses yield that membership involvement is essential in all of the stages of membership in order to develop membership commitment but is not the only factor (because of the partial mediation effect) except for enjoyment in the first year. Enjoyment emerges as crucial to membership commitment at the start of membership, which is underpinned by the complete mediation effect found.

\section{Conclusions and Discussion}

Using an exploratory sequentially mixed method design, the two studies have produced a variety of experiences that together characterize the nature of membership involvement. In the body of experiences, seven beliefs can be distinguished - participation, service, enjoyment, acknowledgement, dedication, togetherness, and identification - that steer the conceptualization of membership involvement (RQ1). The results of study 1 fed the items of study 2 on the basis of which components 'membership involvement', 'membership commitment' and the predictive components 'enjoyment' (in sports and other activities), 'closeness' (social connections) and 'care' (service and support) could be distinguished. Analyses have shown that MI is related to the predictors and the outcome 'membership commitment' (supportive and loyal membership), that MI acts as a mediating factor for membership commitment, and that the duration of membership plays a role, as revealed by the measurements in four stages of membership, $<1$ year, 1-5 years, 6-10 years and $>10$ years membership (RQ2).

\subsection{Membership Involvement Based on Experiences}

The two studies offered insight into the many experiences that young adult members relate to membership involvement. Whereas in previous scholarly work these experiences are often limited to 'participation in sports' [cf 2], the 'service of the sports club' [cf 51, 58] or the 'role as volunteer within the club' [cf 14, 31, 48, 52], our research captured members' involvement as a more elaborate concept by including elements such as 'identification' with the club, 'togetherness' and 'dedication'. Moreover, experiences are reported that underpin members' feelings, such as 'being at home', 'having friends', 'receiving appreciation' and 'having influence', that are important and enriched our knowledge of relevant aspects in developing a members' attachment with a club.

By distilling sensitizing concepts as a first step in study 1 , our research provides a profound understanding of how an amalgamation of experiences may shape membership involvement within the voluntary sports club. The results of study 2 reveal a further conceptualization of membership involvement, driven by predictors and functions as a mediator to membership commitment. Thereby, drawn on the insights in organizational involvement of Etzioni [20] and followers, our research improves the knowledge of membership involvement as the members' 'positive orientation to organizations', in the specific context of member organizations such as VSCs. Building on beliefs that 
are grounded in experiences, our concept of MI offers a lens for looking at the sensemaking processes in the sports clubs $[61,62]$. This sensemaking has been coupled to the concept of involvement because both concepts address experiences as resources within an organization [61, 62]. This understanding of young adults' involvement in membership can be a guideline for building meaningful VSCs. Moreover, membership involvement was found to be a mediator to membership commitment, which underpins the value of MI in developing membership commitment based on experiences. In this way, this research clarifies the distinction between the concepts of involvement and commitment, which are often seen as rather similar concepts $[20,28,58]$.

\subsection{Integrative System of Experiences Predict MI}

Membership involvement, and, consequently, membership commitment is predicted by a combination of three distinct components based on experiences: closeness, enjoyment, and care. In addition to the earlier research within VSCs, in which usually part of the components and underlying experiences were examined, these three components are proposed as an integral system: one component does not function without the others. Drawing on Weick [62], the young adult member experiences teach us about the expectations of members regarding membership. The component 'closeness' refers to experiences such as 'togetherness', 'appreciation', 'having influence'. In general, these senses of community concepts are known for creating trust and solidarity, and they can foster members' attachment to the organization [51, 58] and members' contribution to corporate goals $[35,60]$. 'Enjoyment' expresses beliefs such as 'experiencing fun' and the feeling of 'being at home'. In our results, enjoyment emerges as a key component, and research into sports loyalty in general underpins the obviously important role of enjoyment $[25,36]$. However, little scholarly attention has been paid to enjoyment in VSCs. When it has been studied, it is often related to other observations, such as volunteering or contextual aspects of the VSCs $[32,51]$. In line with prior research, the component 'care' not only incorporates the service and facilities of sports clubs [58] but also the supportive context that clubs offer [51]. In the field of tourism and leisure, caring is a quality that is proven to be important for developing satisfaction and loyalty [45]. Moreover, our research shows that care includes the personal perception of effort of members as deliverers of the service (e.g., experiencing effort and effective communication) and the social context of the club in which this service is offered (e.g., meeting interesting people, expanding social networks). Thus, with this component 'care', VSCs touch upon the essence of the differences within commercial sport organizations with a more consumeristic logic, in which support and solidarity among members is absent $[19,57]$.

Although the component 'constraints' turned out to be of minor importance in the analyses, it identifies experiences and beliefs as control variables. Because these constraints have also emerged in earlier research, such as examining the role perception of members [48] or negative perception of obligatory tasks [52], we included them in our study. The conclusion is justified that members do not seem to be bothered by experiences that have been merged into the component 'constraints' when membership brings an active, pleasant pastime, friendship, and influence on the organization of the club, which is substantiated in the literature $[48,64]$.

\subsection{MI in All Stages of Membership}

Analyzing the influence of 'duration of membership' revealed some remarkable results. In each stage, membership involvement and membership commitment are predicted, which indicates that duration of membership is developed in every stage and does not play a discriminatory role. Moreover, in the first year, the contribution of 'enjoyment' to membership commitment is exclusively explained by MI because of complete mediation, although partial mediation was found in the other cases. This indicates that the factor 'enjoyment' is essential for developing membership involvement and membership commitment in the first year of membership. This corresponds with findings in sports [cf 32, 51] with fundamental literature about community building [60] or the familiarization process (on-boarding) of the new employees [4]. This highlights the importance of the first period of membership, with enjoyment as a central concept. For VSCs, it is crucial to realize this and include this in managerial programs.

\section{Limitations and Further Research}

Our research focused on a specific but important group, young adolescents, due to its characterization as a high-risk group regarding membership retention [10, 12, 41, 42]. Based on this, there are limitations with regard to the external validity, since the results could not easily be generalized, due to the specific sample and the specific context (their VSCs). Although the results offer promising insights into the experiences leading to $\mathrm{MI}$ and bonding of young adults, further research among all age groups is needed for enhancing overall knowledge to membership retention in general.

Findings that the aggregated components 'enjoyment', 'care', and 'closeness' are strongly predictive for MI is an indicator that an integrative system of experiences within a club is important to members. Nevertheless, longitudinal research could gain a thorough understanding of membership involvement based on experiences and beliefs.

\section{Implications}

This mixed method research illustrates that young adults' membership involvement in VSCs can be developed by focusing on an aggregation of experiences, synthesized in an integrated system of components: one cannot do without the other. Thus, pleasure when participating in sports (enjoyment) goes hand in hand with perceiving that things are well arranged (care), and that members at the club form a social community (closeness). This integrative system of experiences determines membership involvement in all 
stages of membership, from less than one year to long-term memberships. These insights offer promising directions for boards in the specific context of member organizations. This research confirms that involvement based on experiences is important for generating supportive and loyal members, members with commitment. Thus, for developing commitment of members of VSCs, developing membership involvement based on positive experiences is crucial.

\section{Conflict of Interest}

All the authors do not have any possible conflicts of interest.

\section{Appendix}

Questionnaire Experiences of Members Regarding Membership Involvement in VSCs

Table 7. Questionnaire Experiences of members regarding Membership Involvement in VCSs.

(1) What's the first thought that comes to mind when you think about membership involvement?

(2) What do you think are the advantages of having membership involvement?

(3) What do you think are the disadvantages of having membership involvement?

(4) Can you describe persons with membership involvement?

(5) Can you describe persons who do not have membership involvement?

(6) What characterizes very supportive members?

(7) What characterizes very loyal members?

(8) What characterizes members who take part in decision making?

(9) Which aspects and circumstances would enable you being more active as a member?

(10) Which aspects and circumstances prevent you from being more active as a member?

\section{References}

[1] AbouAssi, K., \& An, S.-H. (2017). Gender representation and organizational size: examining opportunities for members' involvement in membership organizations. Public Management Review 19 (10), 1437-1454.

[2] Alexandris, K., Douka, S., \& Balaska, P. (2012). Involvement with active leisure participation: does service quality have a role? Managing Leisure, 17 (1), 54-66.

[3] Baron, R., \& Kenny, D. (1986). The moderator-mediator variable distinction in social psychological research: conceptual, strategic, and statistical considerations. Journal of personality and social psychology, 51 (6), 1173-1182.

[4] Bauer, T. N., Bodner, T., Erdogan, B., Truxillo, D. M., \& Tucker, J. S. (2007). Newcomer adjustment during organizational socialization: a meta-analytic review of antecedents, outcomes, and methods. Journal of Applied Psychology, 92 (3), 707.

[5] Beaton, A., Funk, D., Ridinger, L., \& Jordan, J. (2011). Sport involvement: A conceptual and empirical analysis. Sport Management Review, 14 (2), 126-140.

[6] Berridge, K. C., Robinson, T. E., \& Aldridge, J. W. (2009). Dissecting components of reward: 'liking', 'wanting', and learning. Current Opinion in Pharmacology, 9 (1), 65-73.

[7] Blumer, H. (1954). What is wrong with social theory? American sociological review, 19 (1), 3-10.

[8] Bowen, G. A. (2006). Grounded theory and sensitizing concepts. International journal of qualitative methods, 5 (3), 12-23.

[9] Braun, V., \& Clarke, V. (2006). Using thematic analysis in psychology. Qualitative research in psychology, 3 (2), 77-101.

[10] Breuer, C., Hoekman, R., Nagel, S., \& van der Werff, H. (2016). Sport clubs in Europe: A cross-national comparative perspective (Vol. 12). Heidelberg, Germany: Springer.

[11] Burgham, M., \& Downward, P. (2005). Why volunteer, time to volunteer? A case study from swimming. Managing Leisure, 10 (2), 79-93.

[12] Crane, J., \& Temple, V. (2015). A systematic review of dropout from organized sport among children and youth. European physical education review, 21 (1), 114-131.

[13] Creswell, J. W. (2014). Research design: Qualitative, quantitative, and mixed methods approaches. Thousand Oaks: Sage publications.

[14] Cuskelly, G., McIntyre, N., \& Boag, A. (1998). A Longitudinal Study of the Development of Organizational Commitment Amongst Volunteer Sport Administrators. Journal of Sport Management, 12 (3), 181-202.

[15] DeVellis, R. F. (2003). Scale development: theory and applications. 2nd Sage. Thousand Oaks, CA.

[16] Doherty, A., Misener, K., \& Cuskelly, G. (2014). Toward a multidimensional framework of capacity in community sport clubs. Nonprofit and Voluntary Sector Quarterly, 43 (2_suppl), 124S-142S.

[17] Eime, R., Harvey, J., Brown, W., \& Payne, W. (2010). Does Sports Club Participation Contribute to Health-Related Quality of Life? Medicine \& Science in Sports \& Exercise, 42 (5), 1022-1028

[18] Engelberg, T., Zakus, D. H., Skinner, J. L., \& Campbell, A. (2012). Defining and measuring dimensionality and targets of the commitment of sport volunteers. Journal of Sport Management, 26 (2), 192-205.

[19] Enjolras, B. (2002). The Commercialization of Voluntary Sport Organizations in Norway. Nonprofit and Voluntary Sector Quarterly, 31 (3), 352-376. Nonprofit and Voluntary Sector Quarterly, 38 (5), 761-783.

[20] Etzioni, A. (1980). Compliance structures. In Etzioni \& Lehman (Eds.), A sociological reader on complex organizations (3rd ed. ed., pp. 87-130). New York [etc.]: Holt, Rinehart, and Winston. 
[21] Fetters, M. D., Curry, L. A., \& Creswell, J. W. (2013). Achieving integration in mixed methods designs-principles and practices. Health services research, 48 (6pt2), 2134-2156.

[22] Flosdorf, M. L., Carr, B. H., Carr, J. W., \& Pate, J. R. (2016). An Exploration of the Sport Club President's Experience. Recreational Sports Journal, 40 (2), 106-119.

[23] Funk, D. (2017). Introducing a Sport Experience Design (SX) framework for sport consumer behaviour research. Sport Management Review, 20 (2), 145-158.

[24] Funk, D., \& James, J. (2001). Psychological Continuum Model: a Conceptual Framework for Understanding an Individual's Psychological Connection to Sport. Sport Management Review, 4 (2), 119-150.

[25] Funk, D. C., Haugtvedt, C. P., \& Howard, D. R. (2000). Contemporary Attitude Theory in Sport: Theoretical Considerations and Implications. Sport Management Review, 3 (2), 125-144.

[26] Gentile, C., Spiller, N., \& Noci, G. (2007). How to sustain the customer experience: An overview of experience components that co-create value with the customer. European management journal, 25 (5), 395-410.

[27] Gould, S. (1979). An Equity - Exchange Model of Organizational Involvement. The Academy of Management Review, 4 (1), 53-62.

[28] Hallberg, U. E., \& Schaufeli, W. B. (2006). "Same Same" But Different? European Psychologist, 11 (2), 119-127.

[29] Hardesty, D. M., \& Bearden, W. O. (2004). The use of expert judges in scale development: Implications for improving face validity of measures of unobservable constructs. Journal of Business Research, 57 (2), 98-107

[30] Harris, S., Nichols, G., \& Taylor, M. (2017). Bowling even more alone: trends towards individual participation in sport. European Sport Management Quarterly, 17 (3), 290-311.

[31] Hoye, R. (2007). Commitment, involvement, and performance of voluntary sport organization board members. European Sport Management Quarterly, 7 (1), 109-121.

[32] Hyde, M., Dunn, J., Wust, N., Bax, C., \& Chambers, S. (2016). Satisfaction, organizational commitment, and future action in charity sport event volunteers. International Journal of Nonprofit and Voluntary Sector Marketing, 21 (3), 148-167.

[33] Hwang, J., \& Han, H. (2018). A study on the application of the experience economy to luxury cruise passengers. Tourism and Hospitality Research, 18 (4), 478-491.

[34] Jakobsson, B. T., Lundvall, S., Redelius, K., \& Engstrom, L. (2012). Almost all start but who continue? A longitudinal study of youth participation in Swedish club sports. European Physical Education Review, 18 (1), 3-18.

[35] Kellett, P., \& Warner, S. (2011). Creating Communities that Lead to Retention: The Social Worlds and Communities of Umpires. European Sport Management Quarterly, 11 (5), 471-494.

[36] Klaus, P., \& Maklan, S. (2011). Bridging the gap for destination extreme sports: A model of sports tourism customer experience. Journal of Marketing Management, 27 (13-14), 1341-1365.

[37] Kohls, G., Chevallier, C., Troiani, V., \& Schultz, R. T. (2012). Social 'wanting' dysfunction in autism: neurobiological underpinnings and treatment implications. Journal of Neurodevelopmental Disorders, 4 (1), 10.

[38] Kuijsters-Timmers, N., Goedee, J., \& Leenders, R. (2019). Passionate about the sport, dedicated to the club? A systematic review study to the predictors, dimensions, and outcomes of membership involvement in recreational sports and leisure. International journal of human movement and sport sciences, 7 (4), 59-73.

[39] Kyle, G., \& Chick, G. (2004). Enduring leisure involvement: The importance of personal relationships. Leisure Studies, 23 (3), 243-266.

[40] Lindgren, E.-C., Annerstedt, C., \& Dohsten, J. (2017). "The individual at the centre" - a grounded theory explaining how sport clubs retain young adults. International Journal of Qualitative Studies on Health and Well-being, 12 (sup2), 1361782 .

[41] Lucassen, J. M. H., Roest, J. van der, Brandsema, A., Davids, A., Elling, A., Haar, M. T.,... Waardenburg, M. (2018). Sportverenigingen in Nederland. In J. M. H. Lucassen \& J. van der Roest (Eds.). Utrecht / Nieuwegein: Mulier Instituut / Arko Sports Media.

[42] NOC*NSF. (2019). Zo sport Nederland. Trends en ontwikkelingen in sportdeelname (2013-2018), NOC*NSF. www.nocnsf.nl/zosportNederland

[43] Onwuegbuzie, A. J., \& Leech, N. L. (2007). Validity and qualitative research: An oxymoron? Quality \& Quantity, 41 (2), 233-249.

[44] Penley, L. E., \& Gould, S. (1988). Etzioni's model of organizational involvement: A perspective for understanding commitment to organizations. Journal of Organizational Behavior, 9 (1), 43-59.

[45] Pijls, R., Groen, B. H., Galetzka, M., \& Pruyn, A. T. (2017). Measuring the experience of hospitality: Scale development and validation. International journal of hospitality management, 67, 125-133.

[46] Preacher, K. J., \& Kelley, K. (2011). Effect size measures for mediation models: quantitative strategies for communicating indirect effects. Psychological methods, 16 (2), 93.

[47] Pullman, M. E., \& Gross, M. A. (2004). Ability of experience design elements to elicit emotions and loyalty behaviors. Decision sciences, 35 (3), 551-578.

[48] Ringuet-Riot, C., Cuskelly, G., Auld, C., \& Zakus, D. H. (2013). Volunteer roles, involvement, and commitment in voluntary sport organizations: evidence of core and peripheral volunteers. Sport in Society, 17 (1), 116-133. https://doi.org/10.1080/17430437.2013.828902

[49] Sato, M., Funk, D., \& Jordan, J. (2018). Behavioral Correlates of Psychological Involvement: A 2-Year Study. Journal of Sport Management, 1-13. Sport in Society, 17 (1), 116-133.

[50] Schijns, J., Caniëls, M., \& Le Conté, J. (2016). The impact of perceived service quality on customer loyalty in sports clubs. International Journal of Sport Management, Recreation \& Tourism, 24, 42-75.

[51] Schlesinger, T., \& Nagel, S. (2015). Does context matter? Analysing structural and individual factors of member commitment in sport clubs. European Journal for Sport and Society, 12 (1), 53-78. 
[52] Schlesinger, T., Egli, B., \& Nagel, S. (2013). 'Continue or terminate?' Determinants of long-term volunteering in sports clubs. European sport management quarterly, 13 (1), 32-53.

[53] Schulenkorf, N., Giannoulakis, C., \& Blom, L. (2018) Sustaining commercial viability and community benefits: management and leverage of a sport-for-development event. European Sport Management Quarterly, 1-18.

[54] Sotiriadou, P., Wicker, P., \& Quick, S. (2014). Attracting and retaining club members in times of changing societies: The case of cycling in Australia. Managing Leisure, 19 (5), 345-358.

[55] Thiel, A., \& Mayer, J. (2008). Characteristics of Voluntary Sports Clubs Management: a Sociological Perspective. European Sport Management Quarterly, 9 (1), 81-98.

[56] Van Bottenburg, M. (2005). There's no business like sportbusiness. Oratie. Tilburg: Fontys Economische Hogeschool Tilburg.

[57] Van der Roest, J.-W. (2016). Consumerism in sport organizations: conceptualizing and constructing a research scale. European Journal for Sport and Society, 13 (4), 362-384.

[58] Van der Roest, J.-W., Van Kalmthout, J., \& Meijs, L. (2016). A consumerist turn in Dutch voluntary sport associations? European Journal for Sport and Society, 13 (1), 1-18.
[59] Vargo, S. L., \& Lusch, R. F. (2004). Evolving to a new dominant logic for marketing. Journal of marketing, 68 (1), 1-17.

[60] Warner, S., Kerwin, S., \& Walker, M. (2013). Examining sense of community in sport: Developing the multidimensional 'SCS' Scale. Journal of Sport Management, 27 (5), 349-362.

[61] Wegner, C. E., Jones, G. J., \& Jordan, J. S. (2019). Voluntary sensemaking: the identity formation process of volunteers in sport organizations. European Sport Management Quarterly, $19(5), 625-644$.

[62] Weick, K. (1995). Sensemaking in organizations (Vol. 3): Sage.

[63] Weick, K. (2002). Puzzles in organizational learning: an exercise in disciplined imagination. British journal of management, 13 (S2), S7-S15.

[64] Welty Peachey, J., Lyras, A., Cohen, A., Bruening, J., \& Cunningham, G. (2014). Exploring the motives and retention factors of sport-for-development volunteers. Nonprofit and Voluntary Sector Quarterly, 43 (6), 1052-1051-1069. 